\title{
Circannual Alterations in the Circadian Rhythm of Melatonin Secretion
}

\author{
L. A. Thrun, ${ }^{*}$ S. M. Moenter, ${ }^{2}$ D. $\mathrm{O}^{\prime}$ Callaghan, ${ }^{\dagger}$ C. J. I. Woodfill, ${ }^{3}$ and F. J. Karsch ${ }^{* 1}$ \\ *Reproductive Sciences Program, Departments of Biology and Physiology, University of Michigan, \\ Ann Arbor, 48109; +Faculty of Veterinary Medicine, University College Dublin, Dublin 4, Ireland
}

\begin{abstract}
To determine if a circadian rhythm known to be functionally related to the reproductive axis varies on a circannual basis, we monitored the circadian secretion of melatonin at monthly intervals for 2 years in four ovariectomized, estradiol-implanted ewes held in a constant short-day photoperiod. Prior to the study, ewes had been housed in a short-day (8L:16D) photoperiod for 4 years and were exhibiting circannual reproductive rhythms as assessed by serum luteinizing hormone (LH) levels. Three of the four sheep showed unambiguous deviations from the expected nocturnal melatonin secretion at two different times approximately 1 year apart. Nocturnal rises in melatonin, which usually last the duration of the dark phase, were delayed by $3-14 \mathrm{~h}$ or were missing. Altogether, five of the seven melatonin alterations observed in these three ewes occurred during the nadir of the circannual LH cycle. In the remaining ewe, we did not observe an altered melatonin secretory pattern during this period, and this ewe also failed to show a high amplitude circannual cycle of $\mathrm{LH}$. The results provide evidence for a circannual change in the circadian rhythm of melatonin secretion. This alteration in melatonin secretion may serve as a "functional" change in daylength, and thereby may influence the expression of the circannual reproductive rhythm of sheep held in a fixed photoperiod for an extended time.
\end{abstract}

Key Words circannual, circadian, melatonin, luteinizing hormone, reproduction, ewe

\section{INTRODUCTION}

Animals living in seasonally changing environments must accurately time yearly events such as migration, hibernation, and reproduction in order to survive and successfully rear their young. In some cases, these events occur in direct response to seasonal changes in the external environment, such as alterations in ambient temperature, daylength, or food availability (Bronson, 1989). This adaptive strategy

Preliminary report; Biology of Reproduction 46 Supplement 1, 1992.

1. To whom all correspondence should be addressed, at Reproductive Sciences Program, University of Michigan, $300 \mathrm{~N}$. Ingalls Bldg. Rm. 1101 SW, Ann Arbor, MI 48109-0404.

2. Present address: Department of Medicine, Division of Endocrinology, University of Virginia, Box 578, Charlottesville, VA 22908. 3. Present address: Division of STD/HIV Prevention, Centers for Disease Control, 1600 Clifton Rd., Mailstop E63, Atlanta, GA 30333.

JOURNAL OF BIOLOGICAL RHYTHMS, Vol. 10 No. 1, March $199542-54$

(C) 1995 Sage Publications, Inc.

42 
allows the necessary physiological changes to occur rapidly. In many instances, however, physiological adaptations need to begin well in advance of the environmental change. Further, seasonal changes in the environment may vary from year to year (e.g., temperature), or they may not be available to the animal for a large portion of the year (e.g., photoperiod in the case of animals that hibernate). Therefore, in many long-lived species, the mechanisms for generation of seasonal adaptations are internal; that is, they occur in the absence of changes in environmental time cues and are endogenously generated (Gwinner, 1986).

Since the 1960s, numerous investigations have provided strong evidence for the existence of endogenous circannual rhythms in species from a wide spectrum of organisms, including plants, mollusks, fish, reptiles, birds, and mammals (Gwinner, 1986). Although circannual rhythms are known to be widespread, few studies have addressed the mechanisms by which they are produced. One hypothesis is that an interaction exists between the mechanisms for circadian and circannual rhythmicity, such that alterations in the circadian system underlie the generation, or influence the expression, of circannual rhythms (Gwinner, 1986). In this regard, it is of interest that circannual changes in circadian rhythms of activity have been observed in birds and mammals (Gwinner, 1973; Mrosovsky et al., 1976; Lee et al., 1986). For example, the circadian rhythm of wheel-running activity changed spontaneously in association with the circannual rhythm of reproduction in golden-mantled ground squirrels held in a fixed photoperiod (Lee et al., 1986). However, a mechanism by which activity and seasonal reproduction may interact has not been described. The objective of the study reported here was to test the hypothesis that there is a spontaneous change in a circadian rhythm (melatonin) mechanistically related to a circannual rhythm (reproduction) in a photoperiodic, seasonal breeder, the ewe.

The circadian rhythm of melatonin secretion by the pineal gland is regulated by the daily light-dark cycle, and, in mammals, this hormone is crucial to photoperiodic modulation of physiological events (Reiter, 1980; Goldman and Darrow, 1983; Bittman, 1984). In the ewe, melatonin appears to act as a time-keeping hormone that mediates photoperiodic synchronization of the circannual rhythm of reproduction (Malpaux et al., 1988c; Woodfill et al., 1991, 1994). Previous studies in sheep have shown melatonin secretion to be a circadian rhythm that is entrained by the light/dark cycle and that free-runs in constant darkness (Rollag and Niswender, 1976; Lincoln et al., 1985; Wayne, 1988). Our aim, therefore, was to address two questions: Is there a circannual change in the circadian pattern of melatonin secretion in ewes expressing a free-running circannual rhythm of reproductive neuroendocrine activity? If so, are the alterations in this circadian rhythm temporally correlated with circannual changes in reproductive neuroendocrine activity?

\section{METHODS AND MATERIALS}

\section{General}

The experiment reported here was conducted during the last 2 years of an ongoing 6-year study conducted on five Suffolk ewes for the purpose of addressing the existence of a circannual rhythm of reproductive neuroendocrine activity (Karsch et al., 1989). Four of the five ewes survived the duration of the experiment and the data reported are from those four. The ewes were maintained at the Sheep Research Facility near Ann Arbor, Michigan ( $42^{\circ} 18^{\prime} \mathrm{N}$ latitude). Animals were housed in a light-sealed room and were exposed to a fixed short-day photoperiod (8L:16D, lights on $0500 \mathrm{~h} \mathrm{EST}$ ) for a total of 6 years (March 1983 to March 1989). Photoperiod was regulated by electric timers that operated fluorescent bulbs providing an intensity averaging 350 lux lateral to the eyes. A dim $(<2$ lux) red light remained on continuously to facilitate husbandry and nighttime collection of blood for assay of melatonin. Temperature was not regulated. Rams were not present in the room during the study or for 6 years prior to its onset. Animals were fed hay each morning and had free access to mineral licks and water. The ewes were sexually mature when introduced into the fixed photoperiod; ewes \#010 and \#020 were 3 years old and the other two (\#1037 and \#2023) were at least 4 years old as judged by dentition.

\section{Monitoring Circadian Rhythm of Melatonin Secretion}

At approximately monthly intervals during the last 2 years of the 6-year period in constant short-days (April 1987 to March 1989), blood samples were collected at hourly intervals by jugular venipuncture to characterize the circadian pattern of melatonin. Sampling began $2 \mathrm{~h}$ prior to lights-off and continued for either 24 or $48 \mathrm{~h}$. Serum was obtained and stored as described by Karsch and Foster (1975). 


\section{Monitoring Circannual Rhythm of Reproductive Neuroendocrine Activity}

Each ewe was ovariectomized and treated s.c. (subcutaneously) with a $30 \mathrm{~mm}$ estradiol-containing Silastic implant that maintained a constant serum estradiol concentration $(\sim 3 \mathrm{pg} / \mathrm{ml})$ intermediate to that in the luteal and follicular phases of the estrous cycle (Legan et al., 1977; Karsch et al., 1980). By clamping the estradiol level, any possible effects of changing concentrations of circulating steroids on the circadian system were avoided. Levels of circulating $\mathrm{LH}$ in samples obtained twice weekly were used as an index of reproductive neuroendocrine state. In this animal model, circulating LH concentrations change markedly with season, representing shifts in hypothalamic responsiveness to the negative feedback action of estradiol. Under natural environmental conditions, these changes in LH comprise an annual cycle synchronized with the seasons; in the fixed short photoperiod of the present study, this cycle free-runs (Karsch et al., 1989). Once each year the ewes received new implants to ensure that the capsules did not become depleted of estradiol; no noticeable changes in LH concentrations were associated with the implant switches.

\section{Assays}

Melatonin was measured in duplicate $200 \mu \mathrm{l} \mathrm{sam-}$ ples of unextracted serum using a modification (Malpaux et al., 1987) of the radioimmunoassay (RIA) described by English et al. (1986). The limit of detection (two standard deviations from buffer control) averaged $11.4 \mathrm{pg} / \mathrm{ml}$; intra- and interassay coefficients of variation (CV) for two serum pools determined four times in each assay averaged $11.3 \%$ and $13.1 \%$, respectively. LH concentrations were determined in duplicate $25-200 \mu \mathrm{l}$ samples of serum with a modification (Hauger et al., 1977) of the RIA of Niswender et al. (1969). Sensitivity averaged $0.27 \mathrm{ng} / \mathrm{ml}$ for $200 \mu \mathrm{l}$ serum. Mean intra- and interassay CV were $6.6 \%$ and $7.3 \%$, respectively, calculated from values in three serum pools that contained an average of 1.0, 2.2, and $22.9 \mathrm{ng} / \mathrm{ml}$ (determined six times in each assay). Values are expressed in terms of the NIH-LH-S12 standard.

\section{Data Analysis}

Hormone values below assay sensitivity were assigned a value equal to the average limit of detection for purposes of analysis. Circadian cycles of circulat- ing melatonin were analyzed by a procedure described previously (Malpaux et al., 1987). Briefly, for each series of melatonin values, a baseline was defined as the mean of the daytime values preceding and following the dark period by more than $2 \mathrm{~h}$. In every instance, daytime baseline was near or below assay sensitivity. Elevations included all samples exceeding the baseline either by more than 3 standard deviations of the baseline or by more than 3 standard deviations of the buffer controls of the assay, whichever was larger. Previous studies in our laboratory indicate that circulating melatonin rises and falls within 1-2 $\mathrm{h}$ of lights off and on, respectively (Malpaux et al., 1988a). A pattern in which the nocturnal elevation began $\geq 3$ $h$ from the time of lights-off, or was absent during that sampling period, was classified as an altered circadian pattern of melatonin secretion.

LH data for each ewe were first subjected to logarithmic transformation and then analyzed for the existence of a circannual cycle using a cluster analysis algorithm as previously described (Brown et al., 1988; Karsch et al., 1989).

\section{RESULTS}

Figures 1-4 show 24-h melatonin patterns for each sheep over the 2-year sampling period. To facilitate presentation, only every other month of the detailed melatonin patterns are shown in Figures 1-4; melatonin data for all months are summarized in Figures 5-8, co-plotted with circulating $\mathrm{LH}$ concentrations during that period. In addition, only the first $24 \mathrm{~h}$ of the 48-h sampling period are given. In all cases, melatonin patterns during the second $24 \mathrm{~h}$ were similar to those of the first $24 \mathrm{~h}$.

In most instances (71 of 99 circadian patterns), circulating melatonin increased dramatically within $2 \mathrm{~h}$ after lights-out, remained high for nearly the entire 16 $\mathrm{h}$ of darkness, and fell precipitously to baseline within $2 \mathrm{~h}$ of lights on (Figs. 1-4). This is the typical melatonin pattern that we observe in the Suffolk ewe (Malpaux et al., 1987, 1988a, 1988b, 1988c). During certain months, however, there was a dramatic deviation from this pattern. Specifically, elevated concentrations of melatonin were not always evident for a major portion of the dark period. In ewe \#010, for example, the nocturnal rise did not begin until well after (8-9 $\mathrm{h}$ ) lights out during a 5-month period in the second year (July-Nov. in Figs. 1 and 5). In the most extreme case in this ewe, the melatonin rise was completely absent 


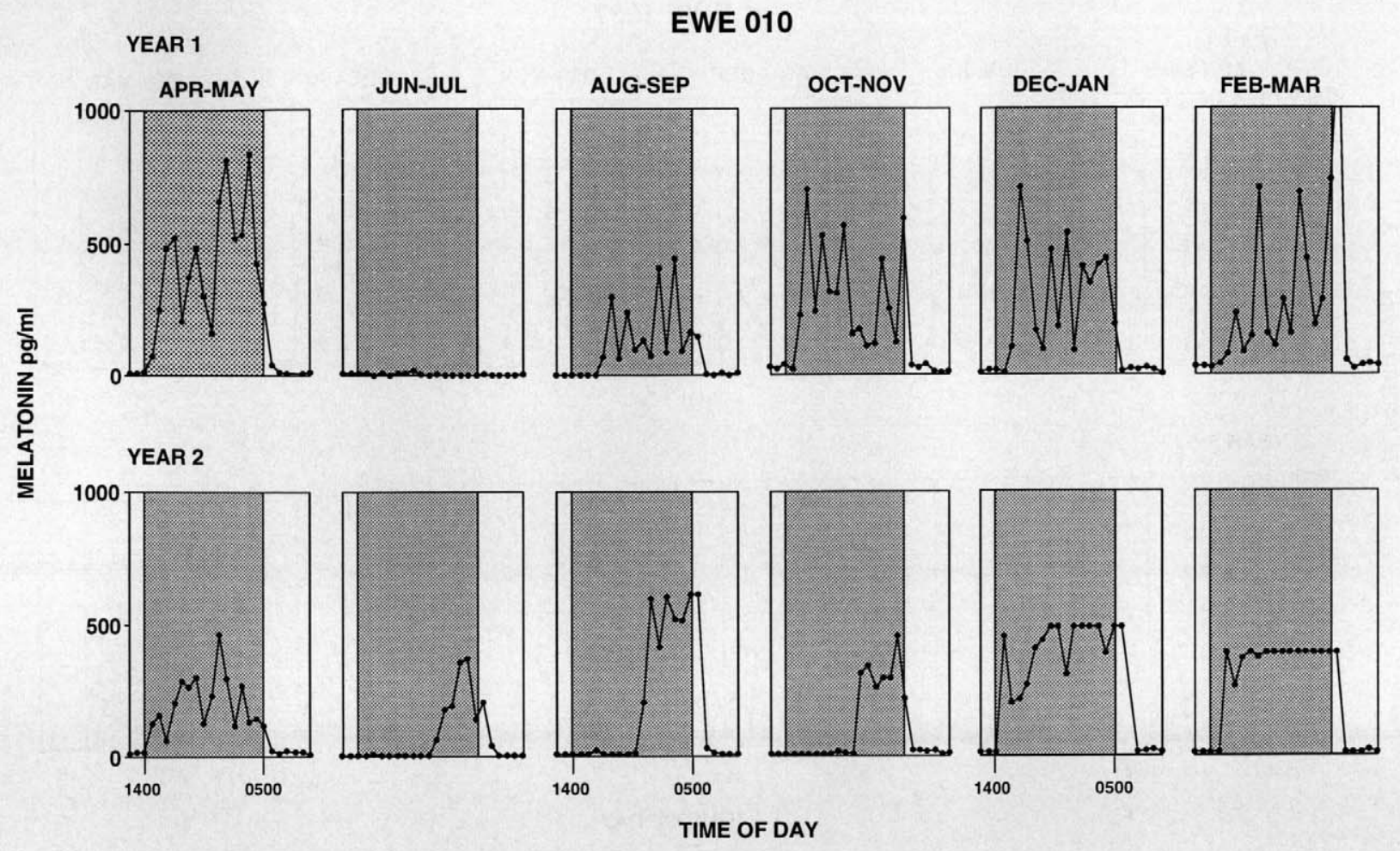

Figure 1. Representative bimonthly 24-h melatonin patterns from short-day hold ewe $\$ 010$ over a 2-year period. Each panel contains a circadian profile representative of the patterns seen during each 2-month period. Shaded areas indicate times of darkness.

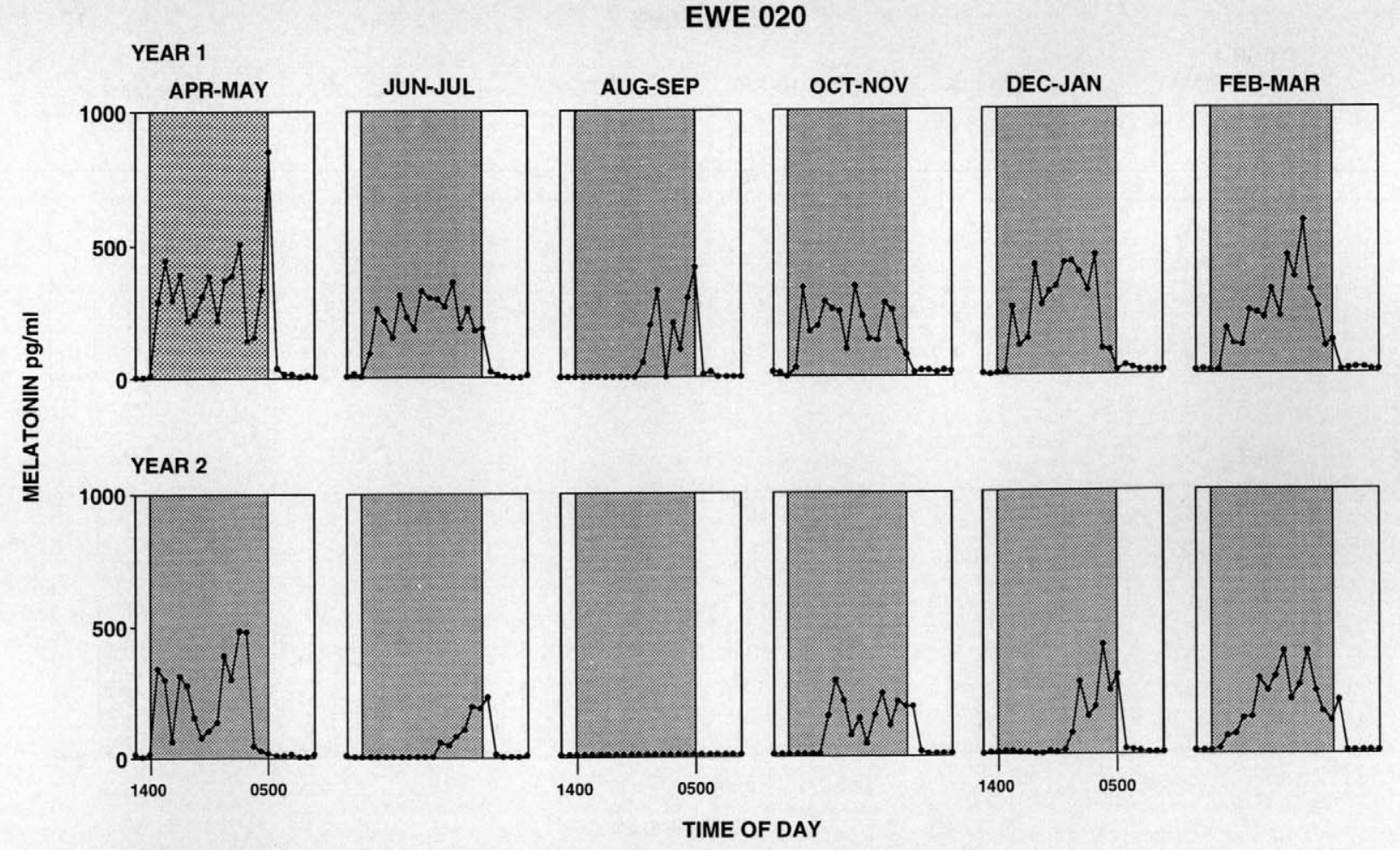

Figure 2. Representative bimonthly 24-h melatonin patterns from short-day hold ewe \#020. Further details in legend for Figure 1. 


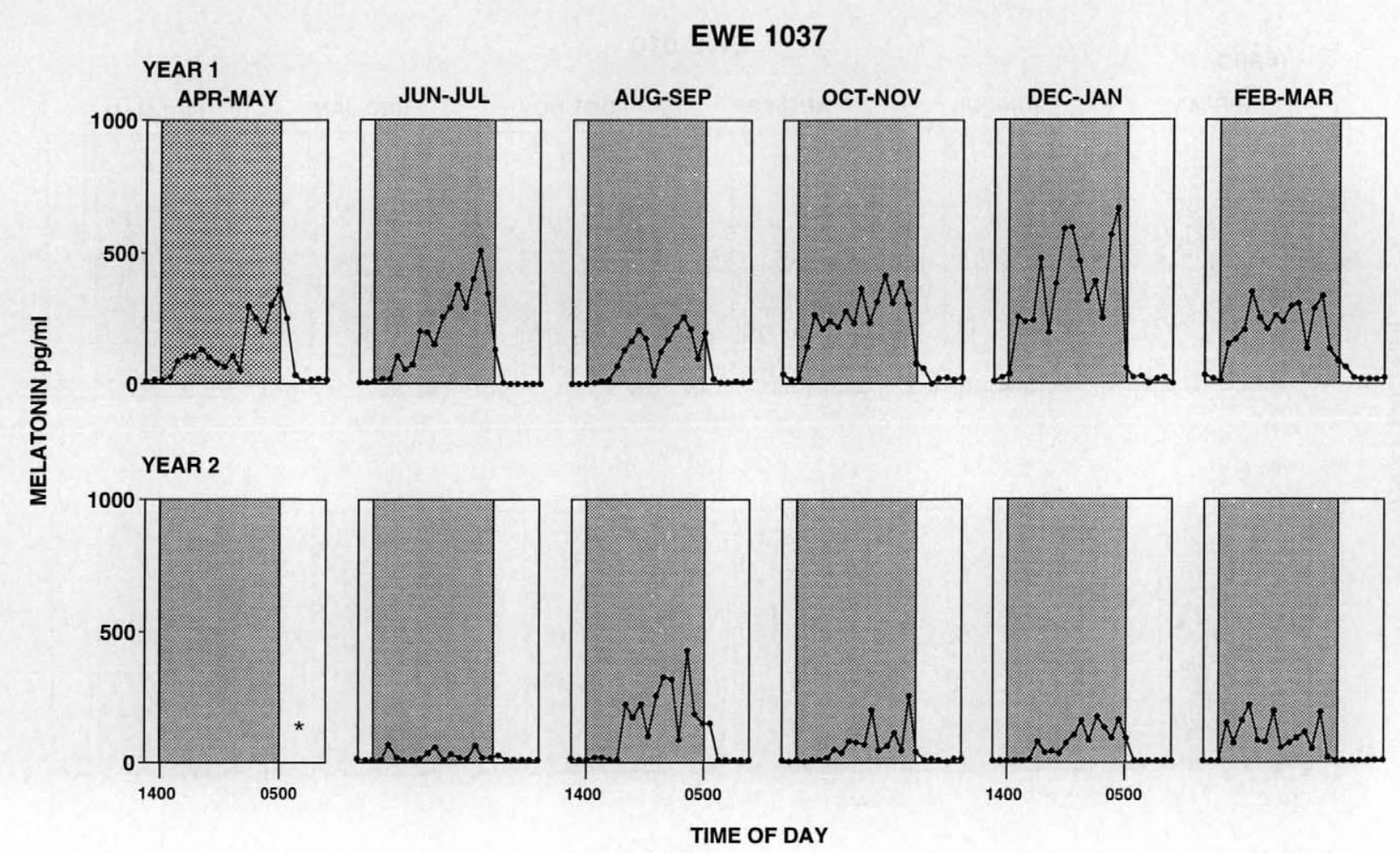

Figure 3. Representative bimonthly 24-h melatonin patterns from short-day hold ewe \#1037. Further details in legend for Figure 1. Asterisk denotes that no data are available for April-May of Year 2.

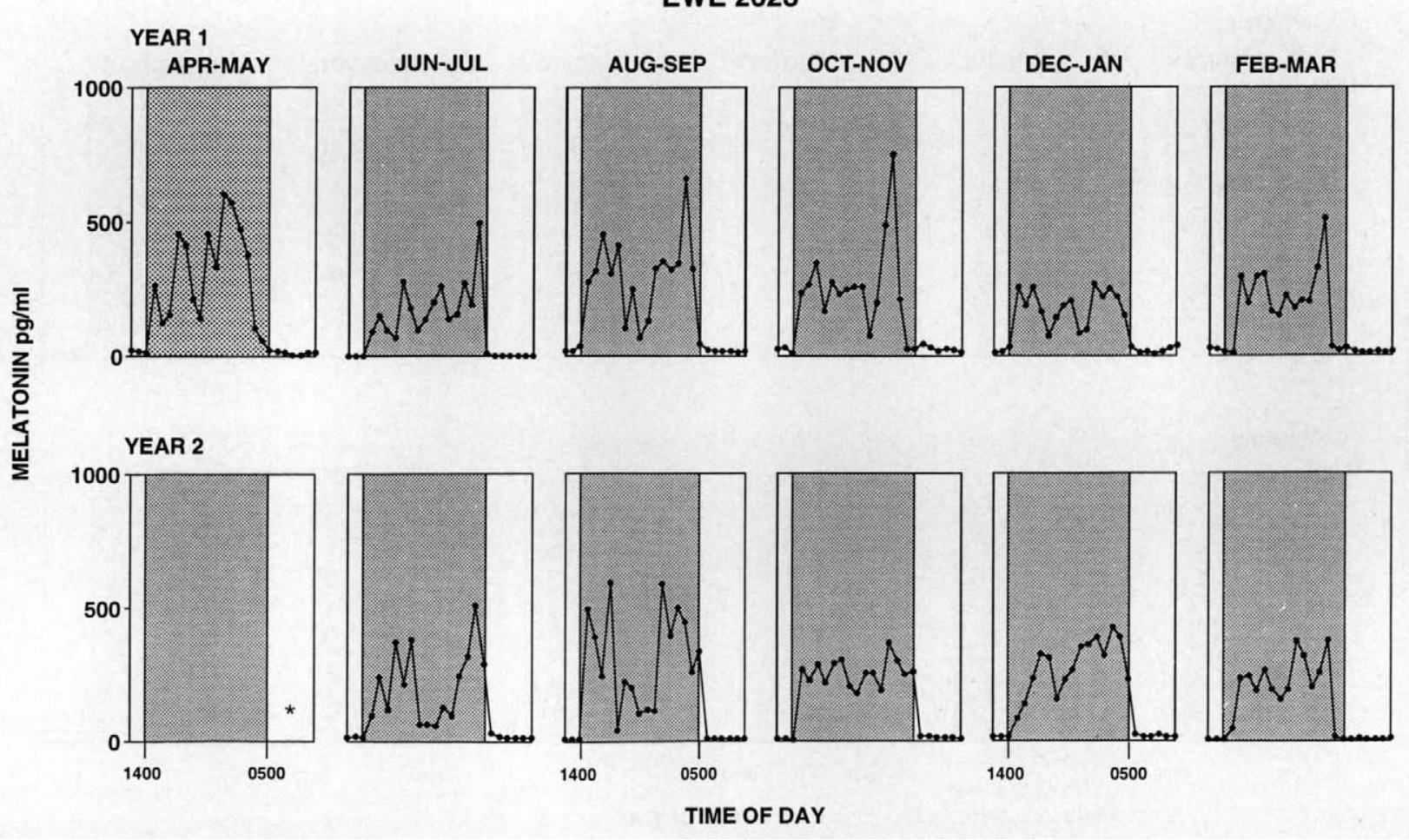

Figure 4. Representative bimonthly 24-h melatonin patterns from short-day hold ewe \#2023. Further details in legend for Figure 1. Asterisk denotes that no data are available for April-May of Year 2. 
Table 1. Period Between Successive Alterations in Circadian Melatonin Secretion and Period of LH Cycles

\begin{tabular}{lcc}
\hline Sheep Number & Melatonin Shifts $^{\mathrm{a}}$ & LH Cycles $^{\mathrm{b}}$ \\
\hline 010 & 398 & 496 \\
020 & 352 & 397 \\
1037 & 411 & 366 \\
2023 & - & $-{ }^{\mathrm{c}}$ \\
Mean \pm s.e.m. & $387 \pm 22$ & $420 \pm 48$ \\
\hline
\end{tabular}

NOTE: s.e.m. = standard error of mean.

a. Number of days between the first circadian melatonin pattern delayed or truncated by $3 \mathrm{~h}$ from lights on or off in Year 1 and the first altered melatonin pattern observed in Year 2.

b. Number of days between onset of high stage of LH concentrations as determined by the algorithm.

c. Cycle dampened, therefore no period is reported (see Fig. 8).

across the 48-h sampling period (June of Year 1, first $24 \mathrm{~h}$ illustrated in Fig. 1).

During the 2 years of sampling, three of the four ewes exhibited at least two periods in which the circadian pattern of melatonin was clearly altered (Figs. 1-3 and 5-7). In each case, the nocturnal increase was delayed by 3-14 $\mathrm{h}$ from the time of lights-off or was absent for that sampling period. The average period between the onset of these alterations ( $387 \pm 22$ days) approximated 1 year in all three ewes (Table 1 ). In one ewe (\#1037), the melatonin alterations observed in the first year were relatively small, but those in Year 2 were more dramatic. Additionally, there were two occasions approximately 8 months apart when no nocturnal increase in melatonin was observed (top of Fig. 7). It is important to emphasize that following the melatonin alterations in each ewe, circulating melatonin eventually returned to its expected pattern of a full nighttime elevation. Further, none of the alterations in the melatonin pattern consisted of elevated values during the daytime hours. In one of the four ewes studied, no major alteration in melatonin was observed (\#2023, Figs. 4 \& 8).

During the 6 years of constant photoperiodic conditions, each of the four ewes exhibited circannual cycles in serum LH concentration. LH patterns during the last 2 years are illustrated at the bottom of Figures 5-8 (see Karsch et al., 1989 for data covering the first 4 years). While most LH cycles were high in amplitude, those of one ewe became dampened during the last 3 years (\#2023; Fig. 8). As with the melatonin alterations, the mean period between $\mathrm{LH}$ cycles approximated 1 year, but periods for individual sheep were highly variable and did not correspond to the interval between alterations in the melatonin patterns (Table 1 ).
It is noteworthy that, with the exceptions of July 1988 and March 1989 in \#1037, the major alterations in melatonin occurred when circulating $\mathrm{LH}$ was relatively low. Even more intriguing is the finding that alterations of melatonin were observed only in the three ewes exhibiting high amplitude LH cycles; no major alteration in the circadian melatonin pattern was seen in the one ewe in which circannual LH cycles became dampened (Fig. 8).

\section{DISCUSSION}

In this study, we found that under a constant shortday photoperiod, the circadian secretion of melatonin varied spontaneously on a circannual basis in three of four ewes examined. Ewes that exhibited these alterations in melatonin secretion displayed distinct, high amplitude circannual cycles of LH. Our findings complement previous observations in warblers and ground squirrels in which circadian activity patterns varied on a circannual basis in association with a circannual rhythm of reproduction under fixed photoperiodic conditions (Gwinner, 1973; Mrosovsky et al., 1976; Lee et al., 1986). Yet, in those previous studies, a mechanism by which circadian activity might influence circannual reproduction was not described. Our present findings therefore extend earlier work by providing evidence for spontaneous circannual changes in a circadian rhythm (i.e., melatonin) known to be involved in the regulation of circannual rhythms.

With regard to the known functional relationship between the circadian melatonin rhythm and the circannual reproductive rhythm, changes in the duration of the nocturnal elevation in melatonin secretion have been found to provide information about changes in daylength to the ewe and thereby to provide a cue for synchronizing the seasonal reproductive rhythm (Woodfill et al., 1991, 1994). In most cases $(\sim 70 \%)$, the patterns of melatonin that we observed accurately represented the fixed short-day photoperiod. The changes that were observed in the remaining instances consisted of delays in the nocturnal elevation of melatonin or elimination of the increase altogether.

Although our findings do not demonstrate a causal relationship between the circadian and circannual mechanisms, it is of interest to consider the possibility that the alterations in melatonin secretion served as a "functional" change in daylength for the ewes held in 


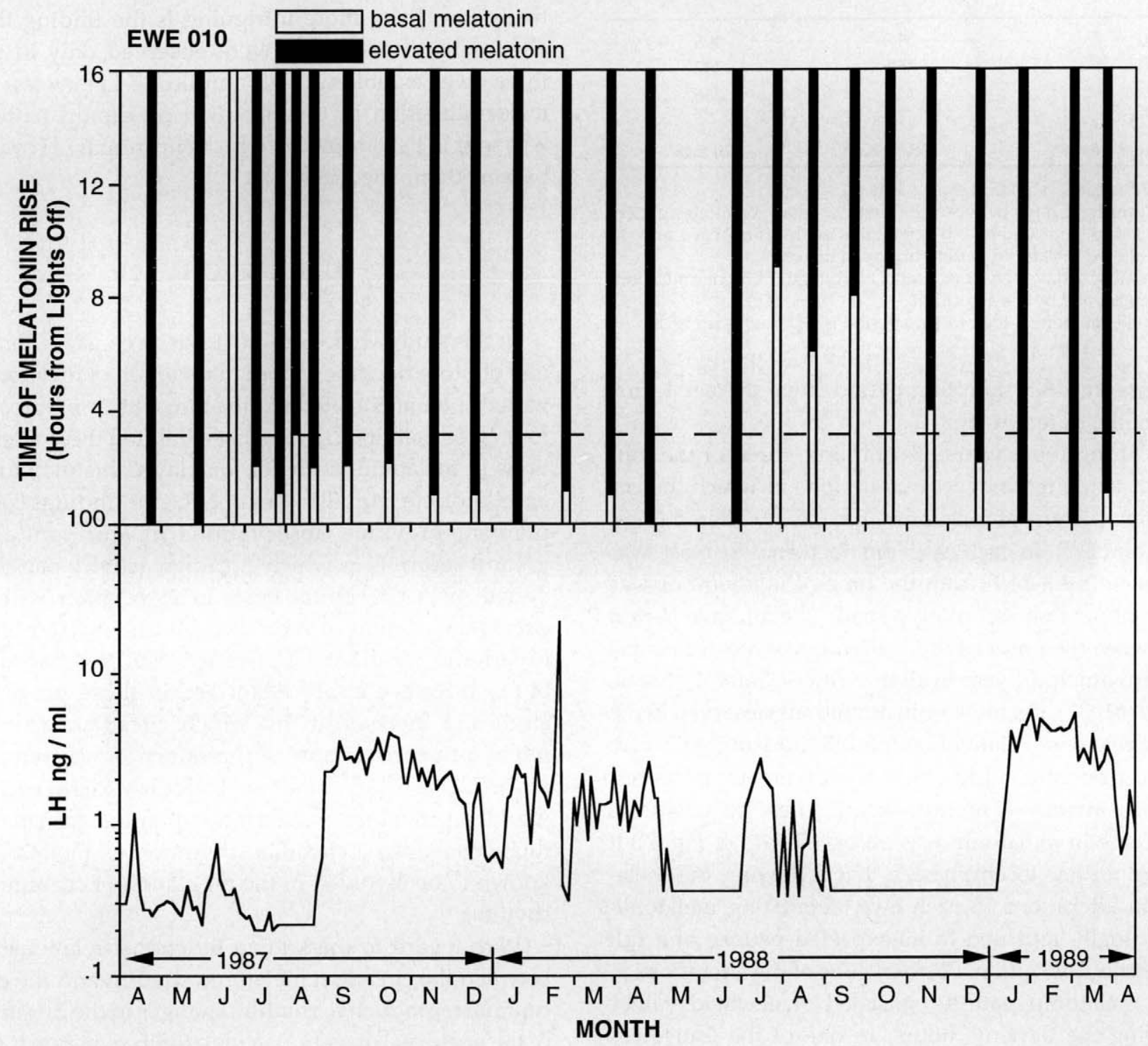

Figure 5. Summary of melatonin patterns observed each month in ewe \#010, co-plotted with the circannual changes in LH concentrations over the 2-year period. The bar graph at the top shows when melatonin concentrations were basal or elevated, relative to time of lights-off. The dark bars represent the total number of hours that melatonin was elevated above basal concentrations during the $16-h$ period when lights were off; the open bars indicate when melatonin concentrations remained basal during the 16-h dark period. The horizontal dashed line denotes $3 \mathrm{~h}$ after lights-off; melatonin secretion beginning at or after this time was considered delayed. The line graph illustrates circannual cycles in LH concentrations observed during the 2-year sampling period.

the constant short-day photoperiod. More specifically, the shortening of the melatonin elevation during the alterations may have mimicked a long day, a signal known to be effective in synchronizing the circannual reproductive rhythm of the ewe (Woodfill et al., 1991). In addition, most of the alterations in circadian mela- tonin secretion occurred during the nadir of the circannual LH cycle; exposure to long days at this time can synchronize the seasonal rhythm of the ewe (Woodfill et al., 1994). Given the temporal relationship between the shifts in nocturnal secretion of melatonin and circannual cycles in $\mathrm{LH}$, it is possible that spontaneous 


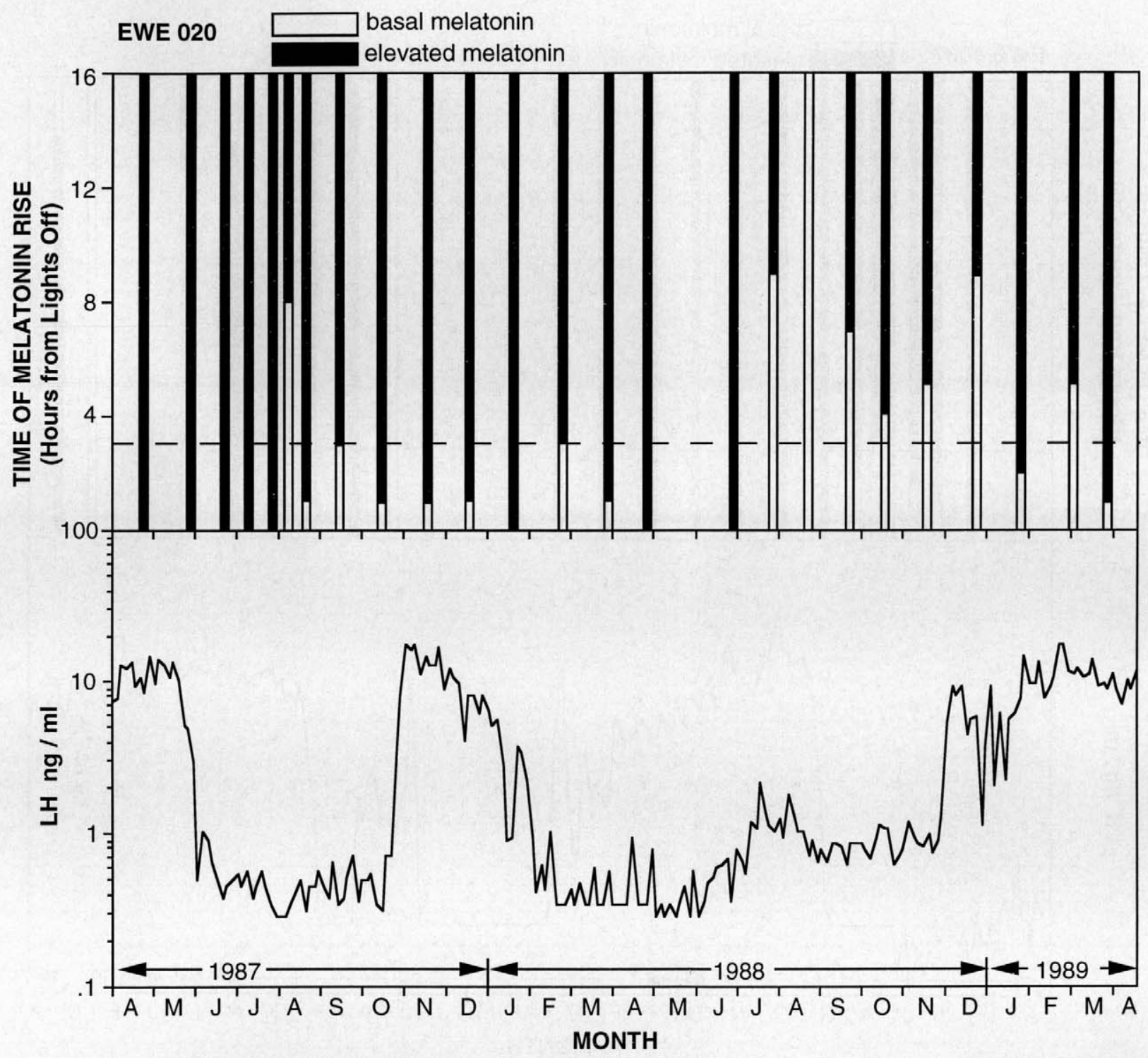

Figure 6. Summary of melatonin patterns observed each month in ewe \#020, co-plotted with the circannual changes in LH concentrations over the 2-year period. Further details in legend for Figure 5.

alterations in the circadian melatonin rhythm influenced the expression of the circannual reproductive rhythm under the conditions of this study. This possibility is reinforced by our finding that the one ewe not exhibiting major alterations in melatonin secretion also failed to display a high amplitude circannual LH cycle.
Because the foregoing interpretation is based on temporal associations, it must be tempered by several considerations. First, it is possible that the alterations in circadian melatonin secretion were not spontaneous but were produced by an environmental factor not controlled in this study. For example, temperature was not regulated and may have been involved in timing 


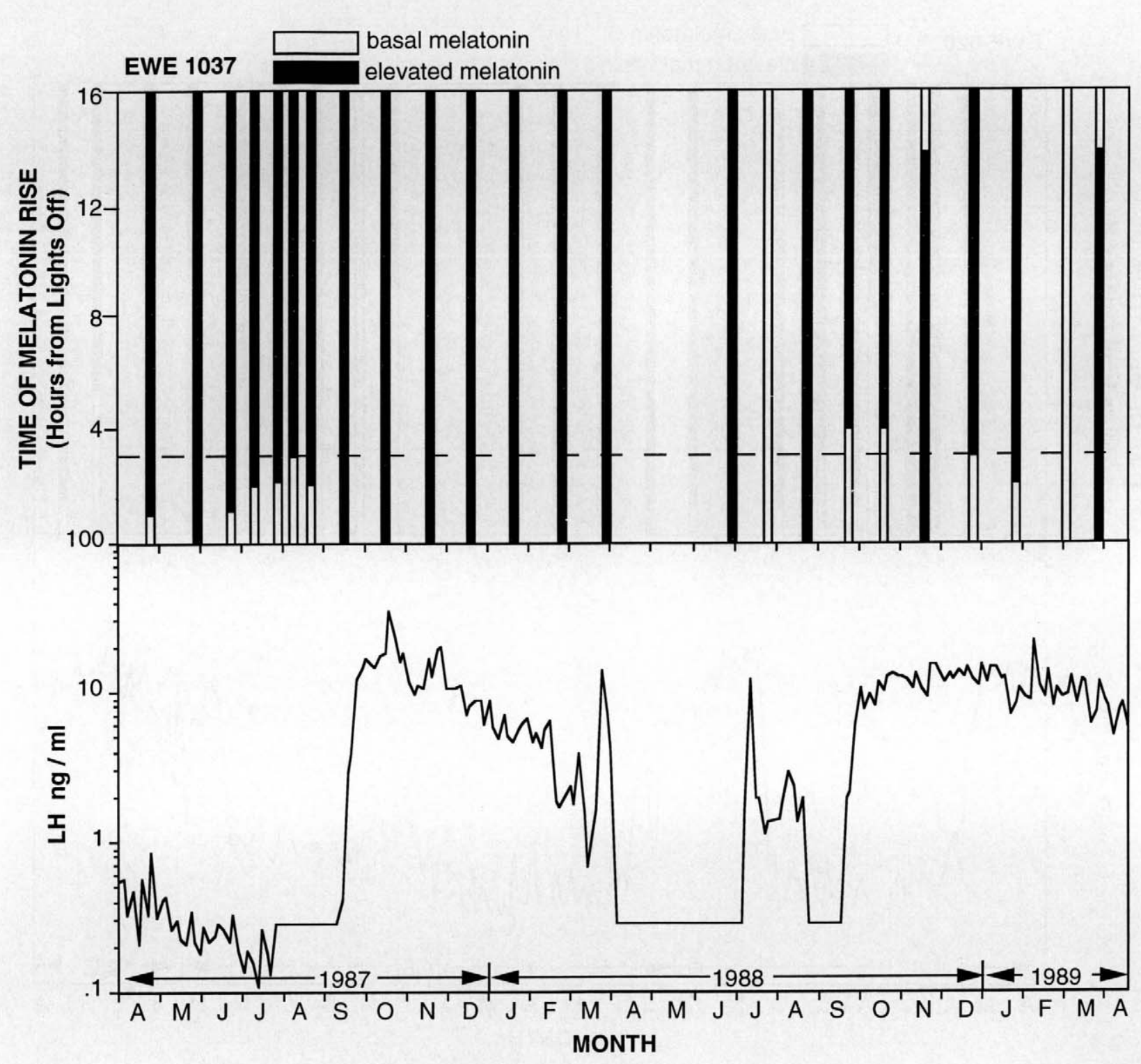

Figure 7. Summary of melatonin patterns observed each month in ewe \#1037, co-plotted with the circannual changes in LH concentrations over the 2-year period. Further details in legend for Figure 5.

or causing the alterations of circadian melatonin secretion. Five of the seven observed periods of altered melatonin secretion occurred during the summer months. It is important to note, however, that the melatonin alterations did not occur at the same time in all ewes and were not observed in one of the four ewes, which would argue against temperature ac- counting for the altered melatonin patterns. This view is strengthened by earlier findings that no delay or absence of the nocturnal increase in melatonin was observed during the summer in our flock of ewes housed under conditions essentially the same as those of the present study (Malpaux et al., 1987, 1988a, 1988b, 1988c). 


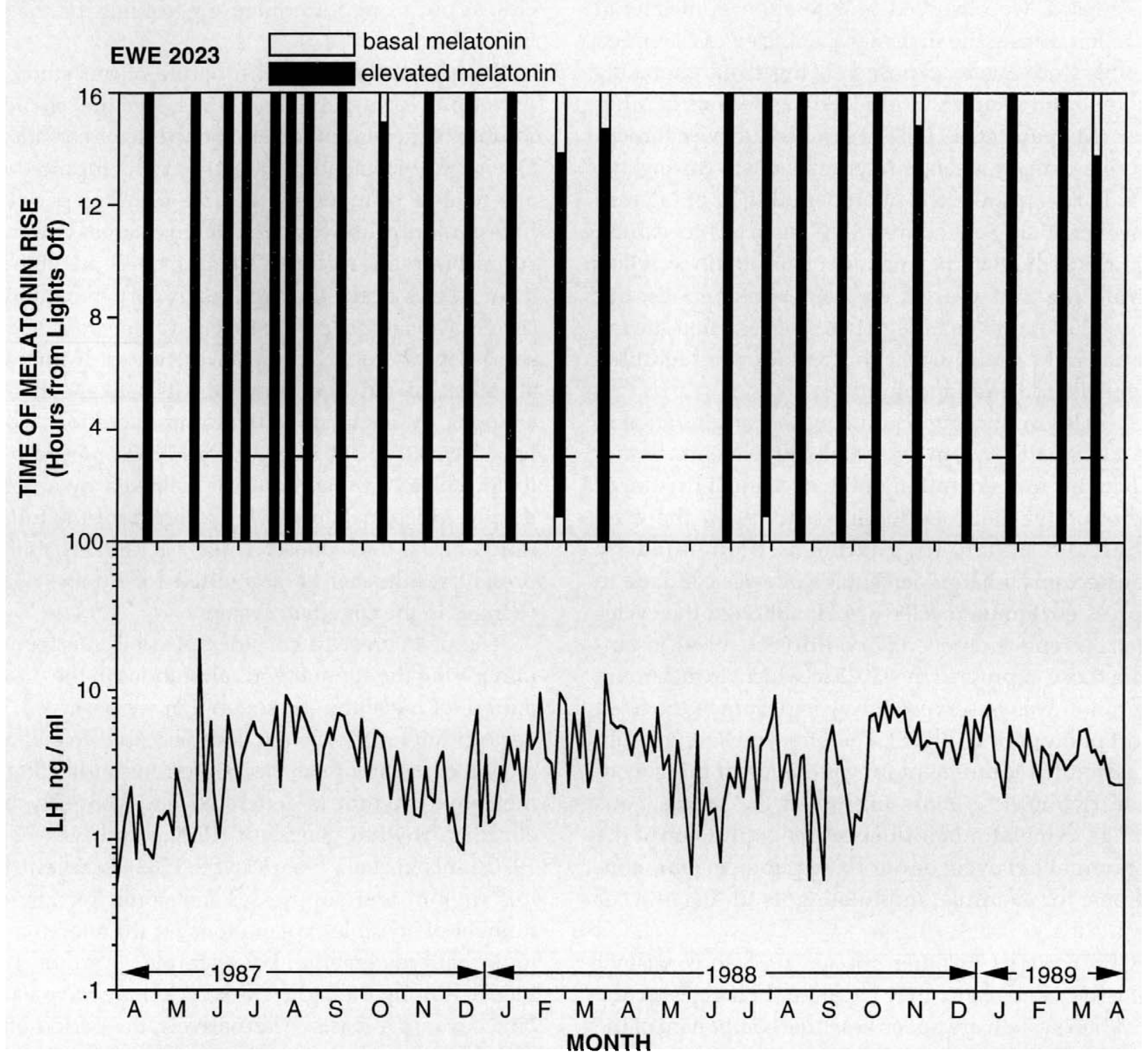

Figure 8. Summary of melatonin patterns observed each month in ewe \#2023, co-plotted with the circannual changes in LH concentrations over the 2-year period. Further details in legend for Figure 5.

A second reservation to the conclusion that there may be a functional interaction between spontaneous alterations in melatonin secretion and the circannual reproductive rhythm is that the coupling of the two rhythms appears to be rather loose. Specifically, the majority of the changes in melatonin occurred during the low stage of the circannual LH cycle, but two of the alterations occurred when LH was elevated. In addition, the period of the LH cycles did not appear to be correlated with the interval between melatonin alterations, although there were too few observations to allow a definitive statement on this point. Also consistent with such a loose coupling between the two types of rhythms is the likelihood that the circannual 
changes in the circadian rhythm of melatonin secretion take a considerable length of time to become established under fixed photoperiodic conditions. In this regard, we observed no alteration in melatonin secretion during the first year that the ewes examined in this study were exposed to the fixed short-day photoperiod (Karsch et al., 1986), as well as in other ewes (Malpaux et al., 1987); yet reproductive neuroendocrine activity changed spontaneously during the initial year in the fixed photoperiod. It is of interest, however, that Soay rams were reported to exhibit changes in the circadian pattern of melatonin secretion during the first year in constant photoperiods, but those alterations included spikes of secretion during the day rather than just the shortening of the nighttime rise (Almeida and Lincoln, 1984)

It is also important to point out that an alteration in the circadian rhythm of melatonin secretion is not obligatory for generation of the circannual rhythm of reproductive neuroendocrine activity in the ewe. When the melatonin rhythm is obliterated by pinealectomy, a large percentage of ewes continue to express circannual cycles of $\mathrm{LH}$, although the cycles often become dampened (Woodfill et al., 1994), resembling those expressed by \#2023 in which no melatonin alteration was observed during exposure to the fixed short photoperiod (Fig. 8). Therefore, melatonin is not an absolute requirement for generation of this circannual rhythm. It is more likely that the spontaneous change in melatonin influences the expression of the circannual LH cycle under fixed photoperiodic conditions; for example, modulating its timing and/or amplitude.

Observations in other species are also consistent with the conclusion that circannual changes in the circadian system are not an essential component of the mechanism for generation of circannual rhythms. In European starlings and golden-mantled ground squirrels, for example, a circannual change in the circadian activity rhythm has been observed (Gwinner, 1973; Mrosovsky et al., 1976; Lee et al., 1986), yet circannual rhythms in these species persist following disruption of circadian rhythmicity by pinealectomy (starlings) or lesion of the suprachiasmatic nucleus (ground squirrels) (Gwinner et al., 1981; Zucker et al., 1983; Dark et al., 1985). Further, in neither of these species was the period of the circannual rhythm altered when the circadian period was manipulated by exposure to light/dark cycles different from 24 hours, as might be expected if the circannual rhythm was produced by 365 cycles of the circadian rhythm (Carmichael and
Zucker, 1986; Gwinner, 1986). This is not to say, however, that circannual changes in the circadian system do not contribute to the expression of circannual cycles, as our present findings suggest may be the case in the ewe.

Because of the long-term nature of our study, the possibility of age-related effects on the circadian rhythm of melatonin secretion needs to be considered. Davis and Viswanathan (1994) recently reported that age-related changes in the free-running period of hamsters are caused by age-related changes within the suprachiasmatic nucleus. Therefore, it is possible that as our ewes aged, they gradually lost the ability to secrete a melatonin profile that accurately reflected the short-day photoperiod they were given. If this were an effect of old age, however, it is likely that the changes in nocturnal melatonin secretion would have persisted, but in every case, each period of altered melatonin secretion was followed by a period during which melatonin was secreted for the full duration of the dark phase. Thus it is unlikely that the present results can be accounted for by age-related changes in the circadian system.

It is of interest to consider possible mechanisms underlying the spontaneous alterations in the diurnal pattern of melatonin secretion that we observed. Under conditions of constant darkness, the circadian secretion of melatonin in sheep free-runs, indicating the melatonin rhythm is generated endogenously by a circadian rhythm generator (Rollag and Niswender, 1976; Lincoln et al., 1985; Wayne, 1988). Light entrains this rhythm and suppresses melatonin secretion. A number of possible explanations for the altered melatonin patterns emerge. For example, entrainment of the rhythm by the light/dark cycle may have varied on a circannual basis. Alternatively, the period of the circadian melatonin rhythm may vary on a circannual basis. Further, there may be a circannual change in the duration of the nocturnal elevation of melatonin. Our study cannot distinguish which, if any, of these possibilities applies. Although the free-running pattern of melatonin during several years of exposure to constant darkness would have aided in interpreting our present findings, the logistics of such an experiment were considered impractical.

Finally, our observation that ewes maintained in a fixed short-day photoperiod can exhibit a circannual change in the circadian rhythm of melatonin secretion raises questions related to the physiological relevance of this phenomenon under natural photoperiodic conditions. Of interest in this regard is the recent report 
that an occasional alteration of the typical melatonin pattern occurred during the anestrous season of Romney ewes maintained outdoors (Scott et al., 1992). Further, in prepubertal Finnish reindeer, temporary disappearance of a previously established circadian melatonin pattern has been observed during the continuous natural darkness of the arctic winter (Eloranta et al., 1992). Thus, although it is possible that the phenomenon identified in the present study is not relevant under natural conditions, it is interesting to consider the possibility that a functional significance may exist. For example, perhaps there is a type of feedback relationship between the circadian and circannual systems of the ewe. In this regard, there is strong evidence that changes in the circadian pattern of melatonin are important in timing the circannual rhythm of reproductive activity (Woodfill et al., 1991, 1994). Perhaps the circannual system reinforces seasonal changes in the circadian system, thereby ensuring appropriate shifts in the pattern of melatonin secretion in accord with the natural photoperiodic cycle and, in turn, appropriate temporal coordination of a number of physiological adaptations to seasonal changes in the environment.

\section{ACKNOWLEDGMENTS}

This research was supported by NIH-HD18337, HD18258, MH 10506, NSF-DCB 871099, IBN 9206510 and the Office of the Vice President for Research at the University of Michigan. We wish to thank Douglas Doop and Kirk Van Natter for their invaluable assistance with the animal experimentation; Barbara Glover for performing RIAs; Drs. Benoit Malpaux and Nancy Wayne for their help in the design and conduct of the study; Drs. Josephine Arendt, G. D. Niswender, and L. E. Reichert, Jr., for supplying assay reagents; and the Sheep Research, Data Analysis, Standards and Reagents, and Administrative Core Facilities of the Center for the Study of Reproduction at the University of Michigan.

\section{REFERENCES}

Almeida OFX and Lincoln GA (1984) Reproductive photorefractoriness in rams and accompanying changes in the patterns of melatonin and prolactin secretion. Biol Reprod 30: 143-158.

Bittman EL (1984) Melatonin and photoperiodic time measurement: Evidence from rodents and ruminants. In The
Pineal Gland, R. J Reiter, ed, pp 155-192, Raven Press, New York.

Bronson FH (1989) Mammalian Reproductive Biology, University of Chicago Press, Chicago.

Brown MB, Karsch FJ, and Malpaux B (1988) An algorithm to identify changes in hormone patterns. Proceedings of the 20th symposium on the interface of computer science and statistics, Reston, VA.

Carmichael MS and Zucker I (1986) Circannual rhythms of ground squirrels: A test of the frequency demultiplication hypothesis. J Biol Rhythms 1: 277-284.

Dark J, Pickard GE, and Zucker I (1985) Persistence of circannual rhythms in ground squirrels with lesions of the suprachiasmatic nuclei. Brain Res 332: 201-207.

Davis FC and Viswanathan N (1994) Restoration of circadian rhythms in aged hamsters by transplantation of the suprachiasmatic nucleus. Abstract No. 7 presented at the fourth meeting of the Society for Research on Biological Rhythms.

Eloranta E, Timisjarvi J, Nieminen M, Ojutkangas V, Leppäluoto J, and Vkkuri O (1992) Seasonal and daily patterns in melatonin secretion in female reindeer and their calves. Endocrinology 130: 1645-1652.

English J, Poulton AL, Arendt J, and Symons AM (1986) A comparison of the efficiency of melatonin treatments in advancing oestrus in ewes. J Reprod Fertil 77: 321-327.

Goldman BD and Darrow JM (1983) The pineal gland and mammalian photoperiodism. Neuroendocrinology 37: 386-396.

Gwinner E (1973) Circannual rhythms in birds: Their interaction with circadian rhythms and environmental photoperiod. J Reprod Fertil Suppl 19: 51-65.

Gwinner E (1986) Circannual Rhythms, Springer-Verlag, Berlin.

Gwinner E, Woznick J, and Dittami J (1981) The role of the pineal gland in the control of annual rhythms. In The Pineal Organ: Photobiology, Biochronometry, Endocrinology, A Oksche and P Pevet, eds, pp 99-121, Elsevier, NorthHolland.

Hauger RL, Karsch FJ, and Foster DL (1977) A new concept for control of the estrous cycle of the ewe based on the temporal relationships between luteinizing hormone, estradiol and progesterone in peripheral serum and evidence that progesterone inhibits tonic LH secretion. Endocrinology 101: 807-817.

Karsch FJ, Bittman EL, Robinson JE, Yellon SM, Wayne NL, Olster DH, and Kaynard AH (1986) Melatonin and photorefractoriness: Loss of response to the melatonin signal leads to seasonal reproductive transitions in the ewe. Biol Reprod 34: 265-274.

Karsch FJ and Foster DL (1975) Sexual differentiation of the mechanism controlling the preovulatory discharge of luteinizing hormone in sheep. Endocrinology 97: 373379.

Karsch FJ, Legan SJ, Ryan KD, and Foster DL (1980) Importance of estradiol and progesterone in regulating $\mathrm{LH}$ secretion and estrous behavior during the sheep estrous cycle. Biol Reprod 23: 404-413.

Karsch FJ, Robinson JE, Woodfill CJ, and Brown MB (1989) Circannual cycles of luteinizing hormone and prolactin 
secretion in ewes during prolonged exposure to a fixed photoperiod: Evidence for an endogenous reproductive rhythm. Biol Reprod. 41: 1034-1046.

Lee TM, Carmichael MS, and Zucker I (1986) Circannual variations in circadian rhythms of ground squirrels. Am J Physiol 250: R831-R836.

Legan SJ, Foster DL, and Karsch FJ (1977) The endocrine control of seasonal reproductive function in the ewe: A marked change in response to the negative feedback action of estradiol on luteinizing hormone secretion. Endocrinology 101: 818-824.

Lincoln GA, Ebling FJP, and Almeida OFX (1985) Generation of melatonin rhythms. Ciba Found Symp 117: 129-148.

Malpaux B, Moenter SM, Wayne NL, Woodfill CII, and Karsch FJ (1988a) Reproductive refractoriness of the ewe to inhibitory photoperiod is not caused by alteration of the circadian secretion of melatonin. Neuroendocrinology 48: 264-270.

Malpaux B, Robinson JE, Brown MB, and Karsch FJ (1987) Reproductive refractoriness of the ewe to inductive photoperiod is not caused by inappropriate secretion of melatonin. Biol Reprod 36: 1333-1341.

Malpaux B, Robinson JE, Brown MB, and Karsch FJ (1988b) Importance of changing photoperiod and melatonin secretory pattern in determining the length of the breeding season in the Suffolk ewe. J Reprod Fertil 83: 461-470.

Malpaux B, Wayne NL, and Karsch FJ (1988c) Termination of the breeding season in the Suffolk ewe: Involvement of an endogenous rhythm of reproduction. Biol Reprod 39: 254-263.
Mrosovsky N, Boshes M, Hallonquist JD, and Lang K (1976) Circannual cycle of circadian cycles in a golden-mantled ground squirrel. Naturwissenschaften 63: 298-299.

Niswender GD, Reichert LE, Jr, Midgley AR, Jr, and Nalbandov AV (1969) Radioimmunoassay for bovine and ovine luteinizing hormone. Endocrinology 84: 1166-1173.

Reiter RJ (1980) The pineal and its hormones in the control of reproduction in mammals. Endocr Rev 1: 109-131.

Rollag MD and Niswender GD (1976) Radioimmunoassay of serum concentrations of melatonin in sheep exposed to different lighting regimens. Endocrinology 98:482-489.

Scott IC, Heath D, and Hawker H (1992) Melatonin secretion in Romney ewes differing in wool growth and reproduction is not aligned to photoperiod during spring and summer. Proc New Zealand Soc Anim Prod 52: 149-152.

Wayne NL (1988) Pineal regulation of seasonal breeding in the ewe: Interaction of environmental signals with endogenous rhythms. Ph.D. Thesis, p. 123, University of Michigan.

Woodfill CJI, Robinson JE, Maulpaux B, and Karsch FJ (1991) Synchronization of the circannual reproductive rhythm of the ewe by discrete photoperiodic signals. Biol Reprod 45: 110-121.

Woodfill CJI, Wayne NL, Moenter SM, and Karsch FJ (1994) Photoperiodic synchronization of a circannual reproductive rhythm in sheep: Identification of season-specific time cues. Biol Reprod 50: 965-975.

Zucker I, Boshes M, and Dark J (1983) Suprachiasmatic nuclei influence circannual and circadian rhythms of ground squirrels. Am J Physiol 244: R472-R480. 